\title{
Molecular and Phylogenetic Analysis of Family Aeshnidae of Hazara Region, Pakistan
}

\author{
Sardar Azhar Mehmood ${ }^{*}$, Manawar Saleem Ahmad², Ahmed Zia ${ }^{3}$, Shabir Ahmed ${ }^{1}$, Muzafar Shah ${ }^{4}$, Wali Khan ${ }^{5}$ and $^{2}$ \\ Waheed Ali Panhwar 6 \\ ${ }^{1}$ Department of Zoology, Hazara University, Mansehra, Pakistan \\ ${ }^{2}$ Department of Zoology, Swabi University, Swabi, Pakistan \\ ${ }^{3}$ National Insect Museum, National Agriculture Research Centre, Islamabad, Pakistan \\ ${ }^{4}$ Department of Zoology, University of Swat, Pakistan \\ ${ }^{5}$ Department of Zoology, University of Malakand, Pakistan \\ ${ }^{6}$ Department of Zoology, Shah Abdul Latif Bahati University, Sindh, Pakistan \\ *For Correspondence: banianhu@gmail.com \\ Received 05 June 2019; Accepted 08 September 2020; Published 10 December 2020
}

\begin{abstract}
Current study was conducted on family Aeshnidae from Hazara region of Pakistan. During the survey a total of 125 members were collected and identified into 2 species under single genus. The present study focuses on molecular characterizations and phylogenetics of family Aeshnidae. Phylogenies of the analyzed taxa were elaborated with maximum likelihood, maximum parsimony and Bayesian analysis. We sequenced both mitochondrial genes i.e., COI and 16S rRNA, separate and combined $\mathrm{CO} 1+16 \mathrm{~S}$ data sets revealed evolutionary relationship within Aeshnidae at the species and genera level. Mean Pairwise Distances (MPD) of each species were ranged from 0.00 to $84.60 \%$. Evolutionary rate differences among two categories Gamma distribution and Invariant were recorded as 0.07 and 1.20 substitutions per site. DNA based identification using CO1, $16 \mathrm{~S}$ and combined $\mathrm{CO} 1+16 \mathrm{~S}$ data set, for all Aeshnidae species shared genetic similarities having bootstrap values MLB=70 $100 \%, \mathrm{MPB}=52-100 \%$ and $\mathrm{BPP}=0.75-1 \%$ respectively. The analysis of the combined $(\mathrm{COI}+16 \mathrm{~S})$ data set produced trees with complete stronger bootstrap support than analyses of either gene alone. These findings had shown that the taxonomic position of Aeshnidae species based on morphological characters could be verified, further improved and confirmed by the use of modern molecular biological tools which involve the nucleotide sequences of genes used in phylogenetic investigations. (C) 2021 Friends Science Publishers
\end{abstract}

Keywords: Aeshnidae; Molecular analyses; Phylogeny; CO1; 16SrRNA; Hazara region

\section{Introduction}

Family Aeshnidae comes under sub order Anisoptera and order Odonata. Aeshnids are worldwide distributed dragonflies with a record of 441 species (Schorr et al. 2009). Regarding Pakistan its six genera and nine species have been reported till to date. Presently 27 species of genus Anax were reported worldwide and four species recorded from Pakistan (Chaudhry 2010). Aeshnid dragonflies are large in size and predators in freshwater ecosystems (Needham and Westfall 1955; Wissinger 1989). Zia et al. (2008) observed that they are important predators of insect pests of agriculturally important crops. Din et al. (2013) and Bhatti et al. (2013) conducted research on their Naiads (larvae) and reported they are voracious predators and consume mosquito larvae and other small crustaceans in large numbers. Besides this, Aeshnid dragonflies also be a significant prey of birds, fishes and few invertebrates thereby playing an important component in food chain of these organisms (Chaudhry 2010).

Taxonomy is the identification of species based on the morphological characters and since it requires vast knowledge about the varied organisms and their characters. In many cases, the conventional taxonomy is difficult due to the external changes in the organisms caused by seasonal and geographical variations, whereas in the case of insects, sexual dimorphism and mimicry often leads to the misidentification of the original species (Mehmood et al. 2016). The incidence of sexual dimorphism is high in insects and aquatic organisms. Many organisms alter themselves physiologically and morphologically due to the unfavorable conditions in the environment. Generally, these variations accumulate in the species and bring about a drastic change in the outlook or appearance of the animals. 
The most common phenomenon exhibited by the insects is to act as a mimic to the model organisms, whereby it is facilitated by anti-predatory effects and habitats survival. On the basis of the above-mentioned difficulties, by adopting manual taxonomy, misidentification of the species may arise. This problem has thus influenced the emergence of the molecular taxonomic frame work studies for the conformation and the betterment in the identification of species (Mehmood et al. 2016).

Although various studies have been conducted in the world to determine the phylogenetics of family Aeshnidae by several workers i.e., The application of COI gene for determining genus-level evolutionary relationships among the several insect taxa (Crozier et al. 1989; Obrower 1994; Simon et al. 1994; Sperling and Hickey 1994; Sperling et al. 1997), including Aeshnid dragonflies (Lunt et al. 1996). Similarly, many workers done study on ribosomal gene, $16 \mathrm{~S}$ rRNA and evaluated the comparison among phylogenetic relationship based on single and combined data sets of CO1 and 16S (Kambhampati and Charlton 1999). Many other workers have studied the molecular characterizations of various odonata species i.e., (Misof et al. 2000; Artiss et al. 2001; Misof et al. 2001; Saux et al. 2003; Hasegawa and Kasuya 2006; Ware et al. 2007a, b, 2008; Bybee et al. 2008; Fleck et al. 2008; Dumont et al. 2010; Davis et al. 2011; Elizabeth et al. 2011; Kohli et al. 2014; Kim et al. 2014; Carle et al. 2015; Bybee et al. 2016; Das 2016; Suvorov 2018; Kalavanti and Jethva 2019).

The objectives of the present research work were to practice the morphometric data, and molecular data which included (COI and 16S) genes to evaluate the major evolutionary association among the species and genera of Aeshnidae dragonflies. Current study represents the Phylgenetic affiliation among the species and genera of Aeshnidae, and established the basis for subsequent comparative studies of morphological and DNA based characterization among the members of family Aeshnidae.

\section{Materials and Methods}

\section{Sample collection and preservation}

Specimens of family Aeshnidae were collected from throughout Hazara region of Pakistan (Fig. 1). Methods of sampling were based on Zia (2010). Method of preservation was based on Chaudhry (2010) and Zia (2010). Adult Odonates were caught with a light and strong insect collection net, during (09 am to $06 \mathrm{pm}$ ) on clear sunny days. Collected specimens were kept in entomological bottles having poured with cyanide; dead members were expansed on setting boards and tagged with complete information such as geographic coordinates, collector's name, date of collection and localities. All the specimens were also placed in deep freezer $\left(-21^{\circ} \mathrm{C}\right)$ for two day for leaning from any fungal contamination. Then the dried specimens were transferred in collection boxes containing naphthalene balls in the National Insect Museum, NARC Islamabad.

\section{Identification}

Taxonomic keys of Chaudhry (2010) and Fraser (1933, 1936) were followed to identify collected specimens up to specific level. Help in identification was also done by using reference collection of Odonata in National insect Museum, National Agricultural Research Centre (NARC) Islamabad.

\section{Molecular study}

Isolation of DNA: Isolation of DNA from dried Aeshnids dragonflies was carried out using Invitrogen (PureLink Genomic DNA) kit applying spin columns with minor modifications in procedure provided by the supplier company. One leg was separated from each specimen through a forcep and placed in a labelled $1.5 \mathrm{~mL}$ micro centrifuge tube while leg was cut into pieces with dissection scissors. After the completion of DNA extraction process, $1 \%$ agarose/TAE gel was used to check the quantity and Quality of the extracted DNA. "UVtec" gel documentation system was used to observe DNA band under "UV" light.

\section{Selection of Primers and PCR amplification}

Primers were selected from NCBI gene bank data available in the literature and the desired sequence of the region which has to be amplified. The isolated genomic DNA was used as template for PCR amplification based on Cytochrome C Oxidase 1 (CO1), and 16S rRNA. The sequences of selected primers are presented as GGTCAACAAATCATAAAGATATGG (F), TAAACTTCAGGGTGACCAAAAAAT CA (R), CGCCTGTTTATCAAAAACAT CTCCGGTTTGAACTCAGATCA(R)

(Mehmood 2016).

\section{Gene sequencing}

The purified DNA of the Aeshnidae dragonflies was sent for sequencing to Macrogen Korea http:/www.macrogen.com. All amplified samples of DNA were successfully sequenced; DNA sequences were BLAST in NCBI GenBank data base for comparison sequences, identification and further Phylogenetic study.

\section{Molecular characterization and Phylogenetic analysis}

Sequences of DNA were aligned applying Muscle alignment (Edgar 2004) and CLUSTAL X 2.1 (Larkin et al. 2007). Aligned data was edited in BioEdit 7.2.5 (Hall 1999). Analyses of Phylogenetic relationship were executed using three methods, Maximum parsimony (MP), Maximum likelihood (ML) and Bayesian analyses (BPP). Maximum parsimony analyses were performed in PAUP4.0b10 (Swofford 2004). Maximum likelihood tree was generated through MEGA6 based on GTRGAMMA model (Tamura 
et al. 2013). Bootstrap was considered $70 \%$ as significant. Bayesian analyses based on Markov chain Monte Carlo (MCMC) and done using the software BEAST 1.6.2 and with the application of (XSEDE) applied on the CIPRES Science Gateway v. 3.3 (Drummond and Rambaut 2007; Miller et al. 2010). To check the ESS value (effective sample size) TRACER 1.5 was implemented (Rambaut and Drummond 2009) Posterior probabilities values (PP) were adjusted greater than $0.95 \%$ as significant. For tree visualization, $\quad$ Fig $\quad$ Tree 1.4 .2 (http://tree.bio.ed.ac.uk/software/figtree), (Rambaut 2012) was used and tree annotating was done through Adobe Illustrator CS6.

\section{Results}

\section{Molecular systematics and phylogenetic analysis based on $16 \mathrm{~S}$ data}

Initially $16 \mathrm{~S}$ rRNA nucleotide sequences were BLAST in GenBank NCBI. The blast result of these species showed 98\% maximum identity $99 \%$ query cover and E-value 0 and 97\% maximum identity $96 \%$ query cover and E-value 0 with A. junuis (AY282557.1) and A. parthenope (EU477651.1) respectively. Mean Pairwise Distances (MPD) of each species were ranged from 0.006 to $47.60 \%$. Evolutionary rate differences among two categories Gamma distribution and invariant $(+\mathrm{G}+\mathrm{I})$ were recorded as 0.11 and 1.89 substitutions per site.

The optimal 16S rRNA tree was obtained with log likelihood -8110.6425 and its bootstrap supported values are presented below the branches (Fig. 2). The 666 positions/characters were used, out of them 1 character was conserved, 665 were variable, 661 were parsimony informative and 5 were single tone sites. The MP technique was based on TBR parameter (Nei and Kumar 2000) with heuristic search of 1000 replicates. The most parsimonious tree was obtained using MP method with length $=2985$ and boot strap supported values are shown above the branches (Fig. 2). The consistency index (CI), retention index (RI) and composite index observed as $0.268342,0.191111$ and 0.051283 respectively. Bayesian Posterior Probabilities (BPPs) is presented below the branches in parenthesis (Fig. 2).

Phylogenetic tree was clustered into two main clades i.e. clade I and II. The clade I was further sub divided into four sub clades. The sub clade I consisted into four species under two different genera. Sub clade II spreaded into four species of genus Aeshna, while subclade III comes under three Aeshna species. Subclade IV comprised of four species of genus Anax including our local species. A. parthenope grouped in subclade IV and showed close relationship with $A$. parthenope (EU477651.1) and its bootstrap supported values were recorded as MLB $=98$, $\mathrm{MPB}=98, \mathrm{BPP}=0.99$ respectively. Clade II come up in to two i.e. subclades, $\mathrm{V}$ and VI. The subclade $\mathrm{V}$ consisted of four species of genus Anax, our local species $A$. immaculifrons clustered in subclade $\mathrm{V}$ and showed close resemblance with A. junius (AY282557.1) and its supported value were recorded $\mathrm{MLB}=97, \mathrm{MPB}=99, \mathrm{BPP}=0.98$. While subclade VI comprised of four species belonging to four different genera (Fig. 2).

\section{Molecular systematics and Phylogenetic analysis based on CO1 data}

For molecular characterization the partial nucleotide sequence of $\mathrm{CO} 1$ gene were obtained for assigning the phylogenetic status of Anax immaculifrons (Rambur 1842) and Anax parthenope (Selys, 1839) belonging to genus Anax and family Aeshnidae. After BLAST analysis of CO1 sequences of these species showed $99 \%$ maximum identity 99\% query cover and E-value 0 and $98 \%$ maximum identity 97\% query cover and E-value 0 with A. nigrofasciatus (KF257056.1) and A. parthenope (KF257072.1) respectively.

Mean Pairwise Distances (MPD) within each species were ranged from 0.087-64.07\%. Differences of evolutionary rate were determined among two categories using a distinct Gamma distribution $(+\mathrm{G}+\mathrm{I})$. Mean evolutionary rates in these categories were recorded as 0.07 and 1.93 substitutions per site.

The ML tree obtained with highest log likelihood (3336.2739), having bootstrap values below the branches (Fig. 3). A total 1147 positions/characters were used, out of them 440 were conserved, 707 were variable, 351 were parsimony informative and 356 were singletone sites. The most parsimonious tree was obtained of length 910 and having supported values above the branches (Fig. 3). The consistency index (CI), the retention index (RI) and the composite index were observed as $0.841758,0.626943$ and 0.527734 respectively. Bayesian Posterior Probabilities (BPPs) is presented below the branches in parenthesis (Fig. $3)$.

The phylogenetic tree generated two major clades, clade I and II, clade I including four species of genus Anax Our local species A. parthenope grouped in clade I and showed close relationship with $A$. parthenope (KF257072.1) and its supported values were recorded as $\mathrm{MLB}=97$, $\mathrm{MPB}=98, \mathrm{BPP}=97 \%$. While local species A. immaculifrons showed homology with Anax nigrofasciatus (Gene Bank accession \# KF257056.1) with supported values $M L B=95$, $\mathrm{MPB}=94, \mathrm{BPP}=0.96 \%$. Clade II comprised of six species under four genera belonging to family Aeshnidae (Fig. 2).

\section{Molecular characterization and phylogenetic analysis based on combined CO1+16S data}

The partial sequences of combined CO1+16S data set were selected for further study. Mean Pairwise Distances (MPD) of each species were ranged from 0.087 to $64.07 \%$. The discrete Gamma Distribution $(+\mathrm{G})$ and invariant $(+\mathrm{I})$ were found 4.0905 and $0.0000 \%$ respectively. 
Mehmood et al. / Intl J Agric Biol, Vol 25, No 1, 2021

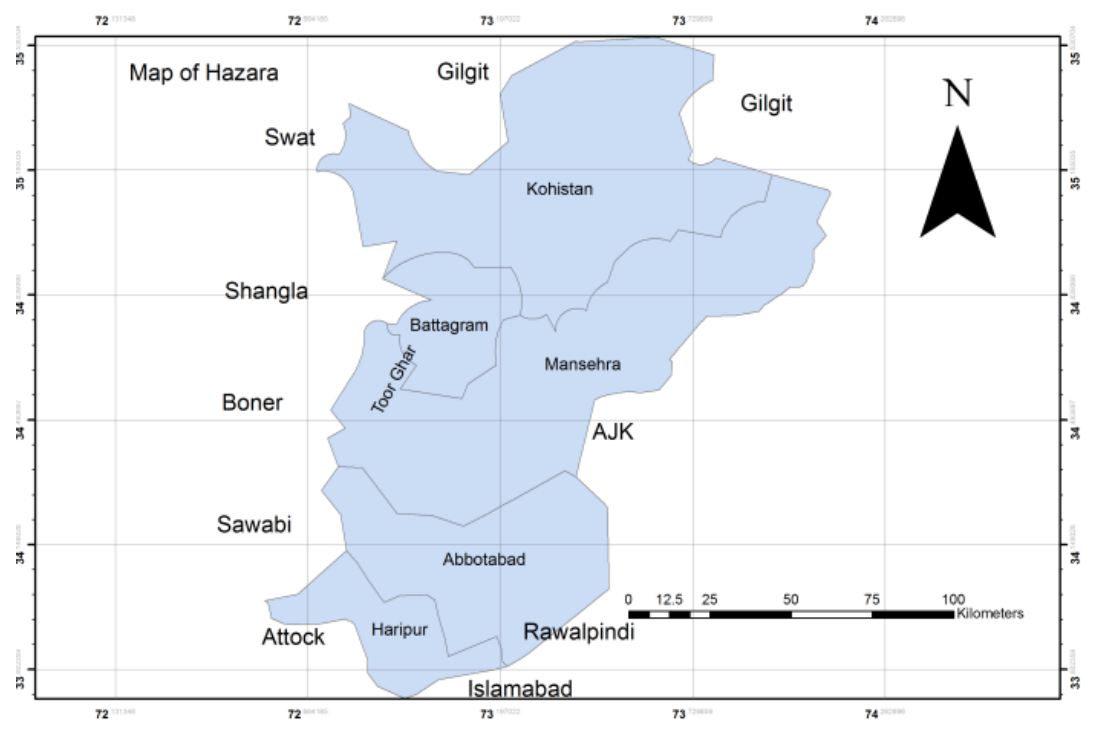

Fig. 1: GIS Map of Hazara Region-Pakistan

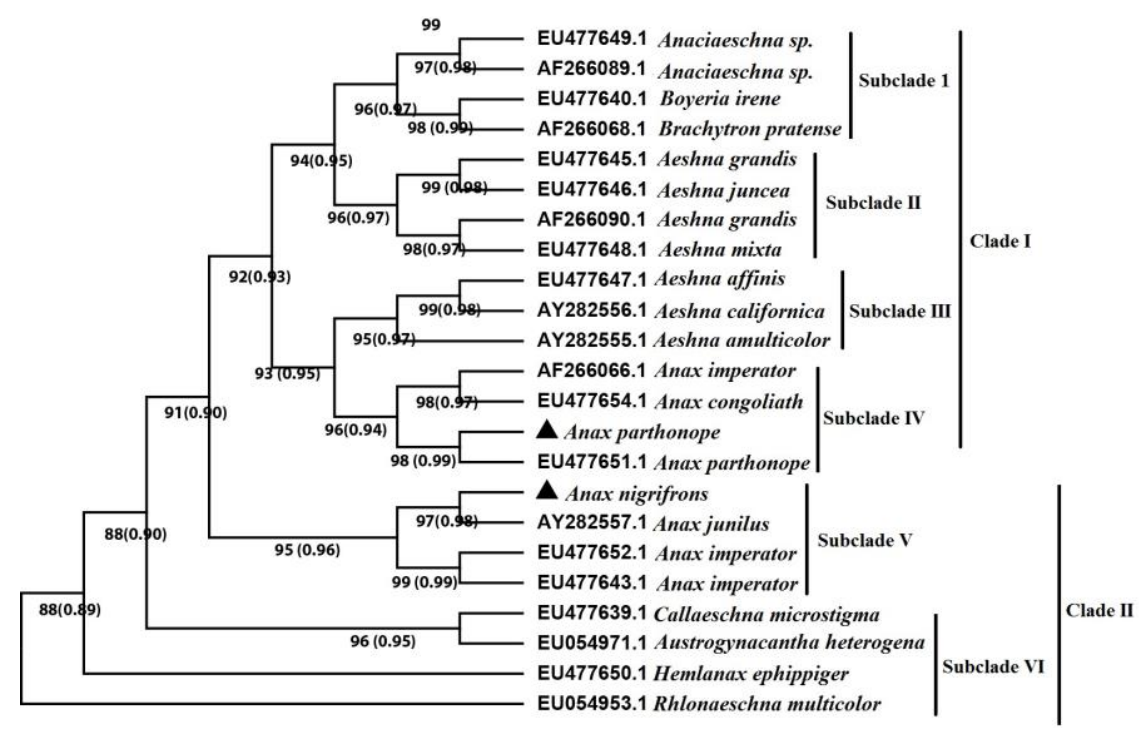

Fig. 2: Phylogenetic tree based on ML analysis of $16 \mathrm{~S}$ gene sequence, Parsimony bootstrap values are given above the branches, Maximum likelihood bootstrap values are presented below the branches and values from posterior probabilities of Bayesian analysis are showed below the branches in parenthesis. Scale bar presented 5 changes per 100 characters (Sequences of the current study)

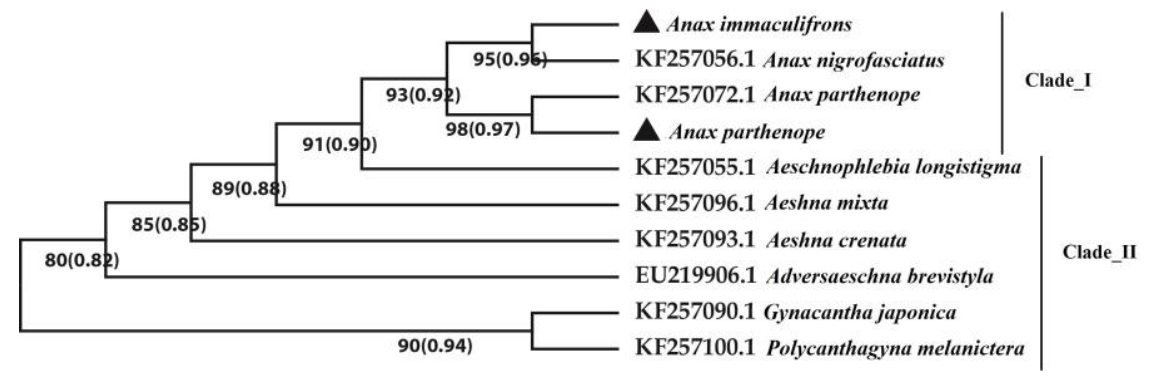

Fig. 3: Phylogenetic tree based on ML analysis of $\mathrm{CO} 1$ gene sequence, Parsimony bootstrap values are given above the branches, Maximum likelihood bootstrap values are presented below the branches and values from posterior probabilities of Bayesian analysis are showed below the branches in parenthesis. Scale bar presented 5 changes per 100 characters (Sequences of the current study) 


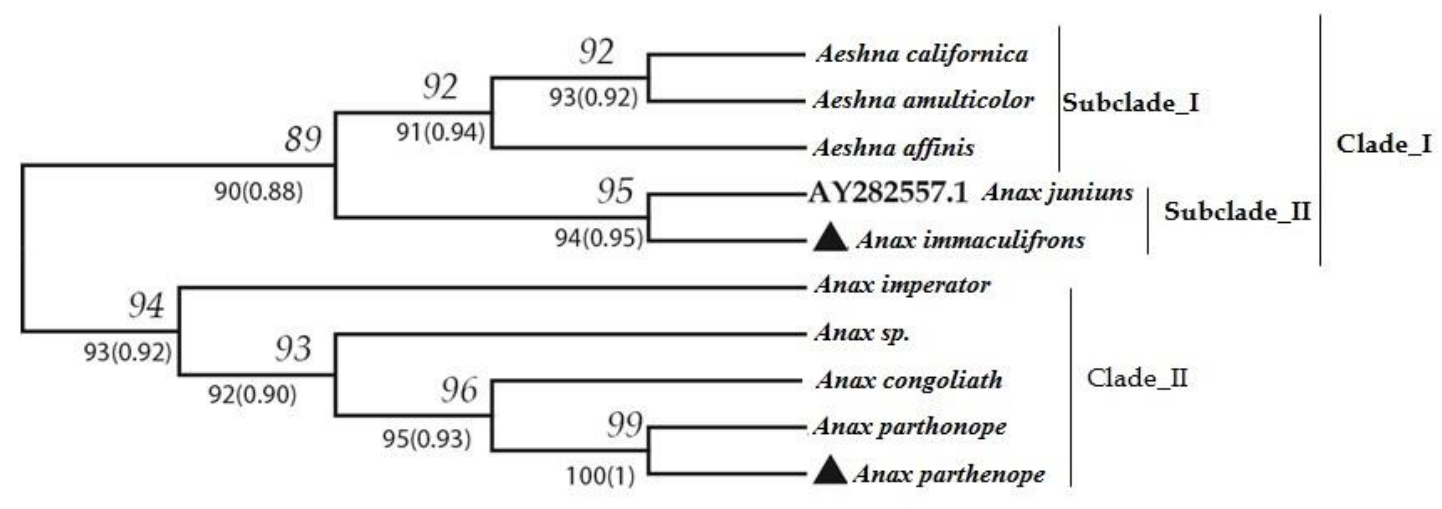

0.05

Fig. 4: Phylogenetic based on ML analysis of CO1+16S data set s, Parsimony bootstrap values are given above the branches, Maximum likelihood bootstrap values were presented below the branches and values from posterior probabilities of Bayesian analysis are showed below the branches in parenthesis. Scale bar presented 5 changes per 100 characters (Sequences of the current study)

The ML tree was obtained with highest log likelihood 10903.7856 having bootstrap values below the branches (Fig. 4). Out of 971 characters/positions, 3 conserved, 968 variable, 940 parsimony informative and 31 singletone sites. The most parsimonious tree was found having length 3228 , with bootstrap values above the branches (Fig. 4). The consistency index (CI), retention index (RI) and composite index was recorded as $0.614312,0.434348$ and 0.266825 respectively. Bayesian Posterior Probabilities (BPPs) are presented below the branches in parenthesis (Fig. 4).

Phylogenetic tree generated into two major clades i.e. clade I and II. The clade I further subdivided into two subclades. Subclade I comprised of three sequences, covering three species under genus Aeshna, whereas subclade II consisted of two species, including our local species Anax immaculifrons and it showed genetic affinities with $A$. junius having supported values as $\mathrm{MLB}=94 \%$, $\mathrm{MPB}=95 \%, \mathrm{BPP}=0.95 \%$. The result of combined $\mathrm{COI}+16 \mathrm{~S}$ data set of $A$. immaculifrons was found similar to the outcomes of $16 \mathrm{~S}$ but differ from CO1 data. Clade II included five sequences covering four species under the genus Anax, including our local species A. parthenope and this species shared genetic similarity with $A$. parthenope with supported values i.e., $\mathrm{MLB}=100 \%, \mathrm{MPB}=99 \%$, $\mathrm{BPP}=1 \%$. The outcomes of combined $\mathrm{COI}+16 \mathrm{~S}$ data set similar to findings of CO1 and 16S individual data analysis with slightly variation of bootstrap supported values (Fig. 4).

\section{Genetic distance among genera of family aeshnidae}

The average number of nucleotide differences (D) and the average number of nucleotide substitutions per site between genotypes (Dxy) were observed. The lowest distance was estimated between Rhinoaeschna and Hemianax ( $\mathrm{D}=8.000$ and $\mathrm{Dxy}=0.02439)$ followed by Rhinoaeschna and Caliaeshna (D=10.000 and Dxy-0.03049) while the highest distances were recorded between Anax and Anaciaeshna $(\mathrm{D}=147.250$ and $\mathrm{Dxy}=0.32081)$ followed by Gynacanth and Anaciaeshna $(\mathrm{D}=147.000$ and $\mathrm{Dxy}=0.32081)$ (Table 1).

\section{Genetic diversity among genera of family aeshnidae}

Genetic diversity among 22 genotypes of family Aeshnidae were estimated, it was revealed that 20 haplotypes resulted with Nucleotide diversity of Anax, Aeshna and other genera $0.17,0.18$ and 0.18 respectively. Haplotype gene diversity was observed i.e., Anax, Aeshna and other genera 0.95, 1.00 and 1.00 respectively. Whereas average number of nucleotide differences k resulted for Anax, Aeshna and other genera 46.76, 53.05 and 54.82 respectively. Fu's Fs test also calculated and it revealed for Anax, Aeshna and other genera 2.81, 0.77 and 0.46 respectively. The value of Tajima's D test was yielded for Anax, Aeshna and other genera -1.61*, $1.65^{*}$ and $-1.73 *$ respectively, (Table 2 ).

\section{Discussion}

Molecular and Phylogenetic results presented here and those of many recent workers (Fleck et al. 2008; Dumont et al. 2010) have clearly supported genus Anax as monophyletic. Our findings based on $16 \mathrm{~S}$ data revealed the clustering of $A$. parthenope and A. immaculifrons with $A$. parthenope (EU477651.1) and A. junius (AY282557.1) respectively.

Whereas analysis of CO1 data showed homology of A. parthenope and A. immaculifrons with $A$. parthenope (KF257072.1) and A. nigrofasciatus (KF257056.1) respectively. The findings of the present molecular study have been justified with previous molecular works of Misof et al. (2001), Ware et al. (2007a, b), Fleck et al. (2008) and Davis et al. (2011) with miner difference of supported values. While the analysis of combined $\mathrm{CO} 1+16 \mathrm{~S}$ data sets recognized the position of $A$. parthenope and $A$. 
Mehmood et al. / Intl J Agric Biol, Vol 25, No 1, 2021

Table 1: Average pair wise differences between genera of family Aeshnidae

\begin{tabular}{|c|c|c|c|c|c|c|c|c|c|}
\hline & Anax & Aeshna & Anaciaeshna & Hemianax & Caliaeshna & Gynacanth & Rhinoaesc & Austrogyn & Boyeia \\
\hline Anax & - & 46.571 & 147.250 & 75.667 & 81.833 & 84.833 & 38.833 & 41.333 & 84.500 \\
\hline Aeshna & 0.16935 & - & 86.429 & 28.571 & 31.714 & 33.143 & 29.571 & 36.286 & 40.000 \\
\hline Anaciaeshna & 0.32081 & 0.29199 & - & 140.500 & 145.000 & 147.000 & 97.000 & 99.500 & 144.000 \\
\hline Hemianax & 0.16378 & 0.09653 & 0.29271 & - & 17.000 & 20.000 & 8.000 & 12.000 & 27.000 \\
\hline Caliaeshna & 0.17751 & 0.10714 & 0.30146 & 0.03448 & - & 26.000 & 10.000 & 16.000 & 27.000 \\
\hline Gynacanth & 0.18362 & 0.11197 & 0.30498 & 0.04040 & 0.05253 & - & 15.000 & 14.000 & 38.000 \\
\hline Rhinoaesc & 0.12901 & 0.09990 & 0.30218 & 0.02439 & 0.03049 & 0.04573 & - & 19.000 & 19.000 \\
\hline Austrogyn & 0.13508 & 0.12300 & 0.30615 & 0.03614 & 0.04819 & 0.04217 & 0.05810 & - & 27.000 \\
\hline Boyeia & 0.19470 & 0.13514 & 0.31718 & 0.05806 & 0.05794 & 0.08137 & 0.05882 & 0.08385 & - \\
\hline
\end{tabular}

Average number of nucleotide differences between populations D (above) Average number of nucleotide substitution per site between populations, Dxy (below) The data was analyzed using DnaSP 5.10 software

Table 2: Values of Genetic diversity of Genus Anax, Aeshna and other genra of family Aeshnidae

\begin{tabular}{llll}
\hline Species & Anax & Aeshna & Other Aeshnidae \\
\hline No of sequences & 7 & 7 & 8 \\
No of haplotypes & 6 & 7 & 8 \\
Nucleotide diversity & 0.17 & 0.18 & 0.16 \\
Standard deviation of nucleotide diversity & 0.10 & 0.11 & 0.09 \\
Haplotype (gene diversity) & 0.95 & 1.00 & 1.00 \\
Variance of haplotype diversity & 0.01 & 0.01 & 0.16 \\
Standard deviation of haplotype diversity & 0.10 & 0.08 & 0.05 \\
Average number of nucleotide differences k & 46.76 & 53.05 & 0.06 \\
Theta & 0.23 & 0.25 & 54.82 \\
Raggedness index & 0.17 & 0.13 & 0.25 \\
Fu's Fs test & 2.81 & 0.77 & 0.05 \\
Tajima's D test & $-1.61^{*}$ & $-1.65^{*}$ & 0.02 \\
\end{tabular}

immaculifrons with $A$. parthenope and A. junius respectively. Similar study was carried out by Bybee et al. (2008) and Carle et al. (2015) have conducted the Phylogenetic studies of Anisoptera and recorded the evolutionary relationship of Anax and Aeshna as supported values $(\mathrm{MLB}=78 \%, \mathrm{BPP}=99 \%)$ and $(\mathrm{BP}=20, \mathrm{PP}=27)$ respectively. Similarly, Saux et al. (2003) conducted phylogenetic study of Aeshnidae while, Kohli et al. (2014) conducted study on genus Boyeria using morphological and molecular markers. Whereas many previous workers studied the molecular characterizations of odonata including members of Aeshnidae i.e., (Misof et al. 2000; Artiss et al. 2001; Misof et al. 2001; Hesgawa et al. 2006; Ware et al. 2008; Elizabeth et al. 2011; Kim et al. 2014; Bybee et al. 2016; Das 2016; Suvorov 2018; Kalavanti and Jethva 2019).

The genetic distance and diversity among the genera of Aeshnidae based on molecular data is presently insufficient to entirely explain the evolutionary relationship among the genera of Aeshnidae. However, the morphological analysis has done by Ellenrieder (2002) provides a topology for evaluation. Whereas according to our findings the genea i.e., Anaciaeshna, Boyeria, Brachytron and Aeshna reusuted as the sister group in constructed phylogenetic tree (Fig. 2, Subclade I and II). While Aeshna also showed genetic affinities with Anax (Fig. 2, Subclade III, IV and V). Our results also support the genus Brachytron and Aeshna in same clade as sister group as described by Ellenrieder (2002). However, the topologies differ in that Boyeria and Caliaeschna do not form a monophyletic group. Two genera Anax and Hemianax were not nested within same clade in our result during the present study. Whereas, Ellenrieder (2002) showed them as close related group. During the present study the genera, i.e., Austrogynacantha, Rhionaeshna, Hemianax, Caliaeshna and Anax were reulted group togather (Fig. 2, Subclade V and VI), similar topology and evolutionary relationship also described by Carle (2012).

\section{Conclusion}

Present work is the first molecular data of Aeshnidae from Hazara region of Pakistan. The molecular techniques of $\mathrm{CO} 1,16 \mathrm{~S}$ and combined $(\mathrm{CO} 1+16 \mathrm{~S})$ presented the superlative outcomes at all. Whereas investigation of $(\mathrm{CO} 1+16 \mathrm{~S})$ data set produced the more precise consequences and Phylogenetic relationship than seperate/single analysis of CO1 and 16S. Throughout the current molecular research Maximum likelihood (ML) Maximum parsimony (MP) and Bayesisn analysis (BA) were used to check the reliability of each method. These methods demonstrated similar evolutionary relationship and topologies only variations were that for some nodes and with minor differences of bootstrap values.

\section{Author Contributions}

SAM \& MSA carried research work, AZ \& MS, prepared the manuscript, WK \& WAP data analyzed and SA proof read the final version of the manuscript for publication 


\section{References}

Artiss T, RT Schultz, DA Polhemus, C Simon (2001). Molecular Phylogenetic analysis of the dragonfly genera Libellula, Ladona, and Plathemis (Odonata: Libellulidae) based on mitochondrial cytochrome oxidase I and 16S rRNA sequence data. Mol Phylogenet Evol 18:348-361

Bhatti AR, A Zia, MI Mastoi, A Din, M Ashfaque, RA Zahid (2013). Fenland naiads of Odonata collected from Tehsil Shakargarh, Punjab, Pakistan. Pak Entomol 36:35-38

Bybee S, AA Córdoba, MD Catherine, R Futahashi, B Hansson, MLC Olalla, R Schilder, R Stoks, A Suvorov, IS Erik, J Swaegers, Y Takahashi, CW Phillip, M Wellenreuther (2016). Odonata (dragonflies and damselflies) as a bridge between ecology and evolutionary genomics. Front Zool 13; Article 46

Bybee SM, HT Ogden, MA Branham, MF Whiting (2008). Molecules, morphology and fossils: Comprehensive approach to odonate phylogeny and the evolution of the odonate wing, Cladistics 23:1-38

Carle FL (2012). A new Epiophlebia (Odonata: Epiophlebioidea) from China with a review of epiophlebian taxonomy, life history, and biogeography. Arthropod Syst Phylogeny 70:75-83

Carle FL, KM Kjer, ML May (2015). A molecular phylogeny and classification of Anisoptera (Odonata). Arthropod Syst Phylogeny 73:281-301

Chaudhry MT (2010). Systematics of Dragonflies (Anisoptera: Odonata) of Pakistan. Ph.D. Thesis. Department of Entomology Faculty of Crop and Food Sciences Pir Mehr Ali Shah Arid Agriculture University, Rawalpindi Pakistan

Crozier RH, YC Crozier, AG Mackinlay (1989). The CO-I and CO-II region of honeybee mitochondrial DNA: Evidence for variation in insect mitochondrial evolutionary rates. Mol Biol Evol 6:399-411

Das SM (2016). Diversity of Odonata in and around the Vivekananda Kendra Vidyalaya (NEC), Baragolai, Margherita, Tinsukia district of Assam (India). Intl J Sci Res Publ 6:406-410

Davis RB, DB Nicholson, ELR Saunders, PJ May (2011). Fossil gaps inferred from phylogenies alter the apparent nature of diversification in dragonflies and their relatives. BMC Evol Biol 11; Article 252

Din A, A Zia, AR Bhatti, MN Khan (2013). Odonata Naiads of Potohar Plateau, Punjab, Pakistan. Pak J Zool 45:695-700

Drummond AJ, A Rambaut (2007). BEAST: Bayesian evolutionary analysis by sampling trees. BMC Evol Boil 7; Article 214

Dumont HJ, A Vierstraete, JR Vanfleteren (2010). A molecular phylogeny of the Odonata (Insecta). Syst Entomol 35:6-18

Edgar RC (2004). MUSCLE: Multiple sequence alignment with high accuracy and high throughput. Nucl Acids Res 32:1792-1797

Ellenrieder NV (2002). A phylogenetic analysis of the extant Aeshnidae (Odonata: Anisoptera). Syst Entomol 27:1-31

Elizabeth, F Ballare, JL Ware (2011). Dragons fly, biologists classify: An overview of molecular odonate studies, and our evolutionary understanding of dragonfly and damselfly (Insecta: Odonata) behavior. Intl J Odonatol 14:137-147

Fleck G, M Brenk, B Misof (2008). Larval and molecular characters help to solve phylogenetic puzzles in the highly diverse dragonfly family Libellulidae (Insecta: Odonata: Anisoptera): The Tetrathemistinae are a polyphyletic group. Org Divers Evol 8:1-16

Fraser FC (1936). The Fauna of British India Including Ceylon and Burma, Vol.1-3.Today and Tomorrow's Printers and Publishers, New Dehli, India

Fraser FC (1933). Fauna of British India, Odonata, Vol. 1-2. Tayler and Francis Ltd., London

Hall TA (1999). BioEdit: A user-friendly biological sequence alignment editor and analysis program for Windows $95 / 98 / \mathrm{NT}$. Available at: https://www.scienceopen.com/document?vid=8b59b929-3c37-49f6936b-f8bf6dd92ace

Hasegawa E, E Kasuya (2006). Phylogenetic analysis of the insect order Odonata using $28 \mathrm{~S}$ and $16 \mathrm{Sr}$ DNA sequences: A comparison between data sets with different evolutionary rates. Entomol Sci 9:55-66

Kalavanti M, B Jethva (2019). A study on diversity and habitat characterisation of Odonata at Nalsarovar bird sanctuary, India. Intl $J$ Sci Res Biol Sci 6:26-34
Kambhampati S, RE Charlton (1999). Phylogenetic relationships among Libellula, Ladona and Plathemis (Odonata: Libellulidae) based on DNA sequence of mitochondrial 16S rRNA gene. Syst Entomol 24:37-41

Kim MJ, KS Jung, NS Park, X Wan, KG kim, J Jun, TJ Yoon, YJ Bae, SM Lee, I Kim (2014). Molecular phylogeny of the higher taxa of Odonata (Insecta) inferred from COI, 16S rRNA, 28S rRNA, and EF1- $\alpha$ sequences. Entomol Res 44:65-67

Kohli MK, T Schneider, O Mueller, JL Ware (2014). Counting the spots: a molecular and morphological phylogeny of the spotted darner Boyeria (Odonata: Anisoptera: Aeshnidae) with an emphasis on European taxa. Syst Entomol 39:190-195

Larkin MA, G Blackshields, NP Brown (2007). Clustal W and Clustal X version 2.0. Bioinformatics 23:2947-2948

Lunt DH, DX Zhang, JM Szymura, GM Hewitt (1996). The insect cytochrome oxidase I gene: Evolutionary patterns and conserved primers for phylogenetic studies. Ins Mol Biol 5:153-165

Mehmood SA (2016). Analysis of species diversity of Odonata in Hazara region of Pakistan through conventional and molecular approaches. Ph.D. Thesis. Department of Zoology, Hazara University, Mansehra, Pakistan

Mehmood SA, MS Khan, A Zia, FA Shaheen (2016). Morphological evaluation of Gomphidae dragonflies of Hazara region of Pakistan through principle component analysis. J Entomol Zool Stud 4:183188

Miller MA, W Pfeiffer, T Schwartz (2010). Creating the CIPRES Science Gateway for inference of large phylogenetic trees. In: Gateway Computing Environments Workshop (GCE), pp:1-8. Institute of Electrical and Electronics Engineers (IEEE), New Jersey, USA

Misof B, AM Rickert, TR Buckley, G Fleck, KP Sauer (2001). Phylogenetic signal and its decay in mitochondrial SSU and LSU rRNA gene fragments of Anisoptera. Mol Biol Evol 18:27-37

Misof B, CL Anderson, H Hadrys (2000). A Phylogeny of the damselfly genus Calopteryx (Odonata) using mitochondrial 16S rDNA markers. Mol Phylogenet Evol 15:5-14

Needham JG, MJ Westfall (1955). A Manual of the Dragonflies of North America (Anisoptera). University of California Press, Berkeley, USA

Nei M, S. Kumar (2000). Molecular Evolution and Phylogenetics. Oxford University Press, Oxford, UK

Obrower AVZ (1994). Phylogeny of Heliconius butterflies inferred from mitochondrial DNA sequences (Lepidoptera: Nymphalidae). Mo Phylogenet Evol 3:159-174

Rambaut A (2012). FigTree. Version 1.4.0. University of Edinburgh, Edinburgh, UK. Available at: http://tree.bio.ed.ac.uk/software/figtree (last accessed May, 2014)

Rambaut A, AJ Drummond (2009). Tracer. MCMC trace analysis tool. Version 1.5. University of Edinburgh, Edinburgh, UK. Available at: http://beast.bio.ed.ac.uk/Tracer (last accessed May, 2014)

Saux C, C Simon, GS Spicer (2003). Phylogeny of Dragonflies and Damselflies order Odonata as inferred by mitochondrial $12 \mathrm{~S}$ ribosomal RNA sequence. Ann Entomol Soc Amer 96:693-699

Schorr M, M Lindeboom, D Paulson (2009). World Odonata list. Homepage on the Internet. http://www.pugetsound.edu/academics/academic-resources/slater museum/biodiversity resources/dragonflies/ world-odonata-list/2009

Simon C, F Frati, A Beckenbach, B Crespi, H Liu, P Flook (1994). Evolution, weighting and phylogenetic utility of mitochondrial gene sequences and a compilation of conserved polymerase chain reaction primers. Ann Entomol Soc Amer 87:651-701

Sperling FAH, DA Hickey (1994). Mitochondrial DNA sequence variation in the spruce budworm species complex (Choristoneura: Lepidoptera). Mol Biol Evol 11:656-665

Sperling FAH, JR Spence, NM Andersen (1997). Mitochondrial DNA, allozymes, morphology, and hybrid compatibility in Limnoporus water striders (Heteroptera: Gerridae): Do they all track species phylogenies? Ann Entomol Soc Amer 90:401-415

Suvorov A (2018). Molecular Evolution of Odonata Opsins, Odonata Phylogenomics and Detection of False Positive Sequence Homology Using Machine Learning. Ph.D. Thesis. Department of Biology Brigham Young University, USA 
Mehmood et al. / Intl J Agric Biol, Vol 25, No 1, 2021

Swofford DL (2004). PAUP*: phylogenetic analysis using parsimony (and other methods), version 4.0b10. Sinauer, Sunderland, Massachusetts, USA

Tamura K, G Stecher, D Peterson, A Filipski, S Kumar (2013). MEGA6: molecular evolutionary genetics analysis version 6.0. Mol Biol Evol 30:2725-2729

Ware JL, SYW Ho, KM Kjer (2008). Divergence dates of libelluloid dragonflies (Odonata: Anisoptera) estimated from rRNA using paired-site substitution models. Mol Phylogenet Evol 47:426-432

Ware JL, E Pilgrim, ML May, TW Donnelly, K Tennessen (2007a). Phylogenetic relationships of North American Gomphidae and their close relatives. Syst Entomol 42:347-358
Ware JL, ML May, KM Kjer (2007b). Phylogeny of the higher Libelluloidea (Anisoptera: Odonata): An exploration of the most speciose superfamily of dragonflies. Mol Phylogenet Evol 45:289-310

Wissinger SA (1989). Seasonal variation in the intensity of competition and predation among dragonfly larvae. Ecology 70:1017-1027

Zia A (2010). Biosystematics of Damselflies (Zygoptera: Odonata) of Pakistan. Ph.D. Thesis. Department of Entomology Faculty of Crop and Food Sciences Pir Mehr Ali Shah Arid Agriculture University, Rawalpindi, Pakistan

Zia A, M Naeem, MA Rafi, SA Hassan (2008). A list of damselflies (Zygoptera: Odonata) recorded from Azad Jammu and Kashmir (AJ\&K). Pak J Sci Ind Res 51:329-332 